Иванова А. Д., Кузнецова О. Р.

A. D. Ivanova, O. R. Kuznetsova

СРАВНЕНИЕ МЕТОДИК АНАЛИЗА ФИНАНСОВЫХ РЕЗУЛЬТАТОВ ХОЗЯЙСТВЕННОЙ ДЕЯТЕЛЬНОСТИ ОРГАНИЗАЦИЙ

\title{
METHODS OF FINANCIAL RESULT ANALYSIS OF ORGANIZATION BUSINESS ACTIVITY
}

Иванова Александра Дмитриевна - магистр кафедры «Экономика, финансы и бухгалтерский учет» Комсомольского-на-Амуре государственного технического университета (Россия, г. Комсомольск-на-Амуре); 681013, Хабаровский край, г. Комсомольск-на-Амуре, пр. Ленина, 27; 8(924)117-29-38. E-mail: www.mikuru_asakura@mail.ru.

Ms. Alexandra D. Ivanova - Master`s Degree student, Economics, Finance and Accounting Department, Komsomolsk-on-Amur State Technical University (Russia, Komsomolsk-on-Amur); 27, Lenin str., Khabarovsk region, Komsomolsk-on-Amur, 681013,+7(924)117-29-38. E-mail: www.mikuru_asakura@mail.ru.

Кузнецова Ольга Рудольфовна - доцент кафедры «Экономика, финансы и бухгалтерский учет», кандидат экономических наук Комсомольского-на-Амуре государственного технического университета (Россия, г. Комсомольск-на-Амуре); 681013, Хабаровский край, г. Комсомольск-на-Амуре, пр. Ленина, 27; 8 (914) 427-55-47. E-mail: www.orkuznetsova@mail.ru.

Ms. Olga R. Kuznetsova - PhD in Economics, Associate Professor, Economics, Finance and Accounting Department, Komsomolsk-on-Amur State Technical University (Russia, Komsomolsk-on-Amur); 27, Lenin str., Khabarovsk region, Komsomolsk-on-Amur, 681013, 8(914)427-55-47. Email: www.orkuznetsova@mail.ru.

Аннотация. В данной статье раскрыто понятие финансового анализа, рассмотрены различные методики анализа финансовых результатов организаций. Проведен сравнительный анализ трех методик, выявлены их достоинства и недостатки.

Summary. The article covers the concept of financial analysis, consideres various methods of analysis of the company financial results. A comparative analysis of the three methods identifies their strength and weakness.

Ключевые слова: финансовый анализ, финансовый результат, прибыль, выручка, рентабельность, методы финансового анализа, методика А. Д. Шеремета, методика Н. Н. Селезневой, Инэк, финансовый аналитик, внутрихозяйственный анализ.

Key words: financial analysis, financial result, earnings, revenue, profitability, methods of financial analysis, methods of A. D. Sheremet, methods of N. N. Selezneva, INEC, financial analyst, intercompany analysis.

УДК 336.71

Основная цель финансового анализа - это получение нескольких ключевых параметров, которые дают объективную и точную картину финансового состояния организации, изменений в структуре активов и пассивов, в расчетах с дебиторами и кредиторами, в том числе и ее финансовых результатов [1]. Финансовый результат, в свою очередь, - конечный экономический итог хозяйственной деятельности организации, выражающийся в форме прибыли или убытка. Прибыль является одним из критериев эффективности деятельности предприятия и главным внутренним источником формирования его финансовых результатов. В условиях современной рыночной экономики необходимо поддерживать достаточный уровень прибыльности для нормального функционирования организации. Для этого нужно правильно подобрать методику анализа финансовых результатов.

Основные правила чтения (методики анализа) финансовых отчетов выработаны практикой финансового анализа. Среди них можно выделить шесть основных методов (см. табл. 1) [5]. 


\begin{tabular}{|c|c|}
\hline 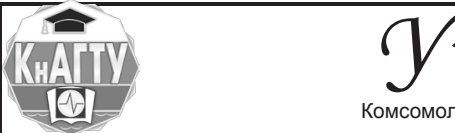 & 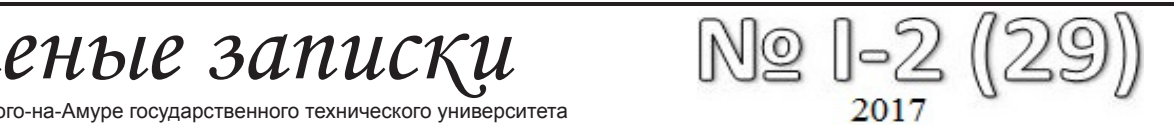 \\
\hline & Таблица 1 \\
\hline & Методы финансового анализа \\
\hline Наименование & Определение \\
\hline 1 Горизонтальный анализ & Сравнение каждой позиции отчетности с предыдущим периодом \\
\hline 2 Вертикальный анализ & $\begin{array}{l}\text { Определение структуры итоговых финансовых показателей с выяв- } \\
\text { лением влияния каждой позиции отчетности на результат }\end{array}$ \\
\hline 3 Трендовый анализ & $\begin{array}{l}\text { Сравнение каждой позиции отчетности с рядом предшествующих } \\
\text { периодов и определение тренда, т.е. основной тенденции динамики } \\
\text { показателя }\end{array}$ \\
\hline $\begin{array}{l}4 \text { Анализ относительных } \\
\text { показателей }\end{array}$ & $\begin{array}{l}\text { Расчет отношений между отдельными позициями отчета или пози- } \\
\text { циями разных форм отчетности, определение взаимосвязей показа- } \\
\text { телей }\end{array}$ \\
\hline 5 Сравнительный анализ & $\begin{array}{l}\text { Анализ показателей данной фирмы с показателями конкурентов, со } \\
\text { среднеотраслевыми и средними хозяйственными данными }\end{array}$ \\
\hline 6 Факторный анализ & $\begin{array}{l}\text { Анализ влияния отдельных факторов на результативный показатель } \\
\text { с помощью детерминированных или стохастических приемов ис- } \\
\text { следования }\end{array}$ \\
\hline $\begin{array}{r}\text { Вышеперечисленны } \\
\text { ны для обеспечения упрг } \\
\text { устойчивости в условиях р } \\
\text { Существует множес } \\
\text { Рассмотрим подроб } \\
\text { зяйственной деятельности: } \\
\text { 1) методику А. Д. Ш } \\
2 \text { ) методику Н. Н. С } \\
3) \text { методику програл } \\
\text { Анализ по методик } \\
(1-4) . \text { Прибыль как фина } \\
\text { налогооблагаемая, чистая. }\end{array}$ & $\begin{array}{l}\text { методы финансового анализа, выработанные практикой, предназначе- } \\
\text { ения финансовым состоянием организации и оценки финансовой } \\
\text { гочной, экономики [2]. } \\
\text { о подходов к анализу финансовых результатов. } \\
\text { е } 3 \text { методики анализа финансовых результатов и эффективности хо- } \\
\text { емета; } \\
\text { езневой; } \\
\text { ного комплекса «Инэк. Финансовый аналитик». } \\
\text { А. Д. Шеремета начинается с формирования показателей прибыли } \\
\text { овый результат выступает в следующих формах: валовая, от продаж, }\end{array}$ \\
\hline & $\Pi_{\text {вал }}=\mathrm{B}_{\text {вал }}-\mathrm{C}$ \\
\hline $\begin{array}{r}\text { где П вал - валовая прибыль, } \\
\text { Валовая выручка, в } \\
\text { стиционной деятельности, } \\
\text { ченный от реализации услу }\end{array}$ & $\begin{array}{l}B_{\text {вал }} \text { - валовая выручка, p.; С - себестоимость товаров, работ, услуг, } \mathrm{p} \text {. } \\
\text { ою очередь, состоит из поступлений от основной деятельности, инве- } \\
\text { инансовой деятельности. Прибыль от продаж - это результат, полу- } \\
\text { имущества организации и так далее }\end{array}$ \\
\hline & $\Pi_{\text {прод }}=\Pi_{\text {вал }}-\mathrm{P}_{\mathrm{\kappa}}-\mathrm{P}_{\mathrm{y}}$ \\
\hline $\begin{array}{r}\text { где П прод - прибыль от про } \\
\text { Налогооблагаемая г } \\
\text { гообложения, рассчитанна } \\
\text { является базой исчисления }\end{array}$ & $\begin{array}{l}\text { ж, р.; } \mathrm{P}_{\text {к }} \text { расходы коммерческие, } \mathrm{p} . ; \mathrm{P}_{\text {y }} \text { - расходы управленческие, p. } \\
\text { тбыль - декларируемая в налоговые органы сумма прибыли до нало- } \\
\text { учетом предоставленных затрат и порядка ее налогообложения, она } \\
\text { алога на прибыль }\end{array}$ \\
\hline & $\Pi_{\text {дн }}=\Pi_{\text {прод }}+Д_{0}-P_{o}+Д_{п р}-P_{п р}$ \\
\hline $\begin{array}{l}\text { где } \Pi_{\text {дн }}-\text { прибыль до нало } \\
\text { онные, р.; } Д_{п р}-\text { доходы пр }\end{array}$ & $\begin{array}{l}\text { обложения, p.; Д - доходы операционные, p.; } \mathrm{P}_{\text {o }} \text { - расходы операци- } \\
\text { ие, } р . ; \mathrm{P}_{\text {пр }}-\text { расходы прочие, } \mathrm{p} .\end{array}$ \\
\hline
\end{tabular}


Иванова А. Д., Кузнецова О. Р.

СРАВНЕНИЕ МЕТОДИК АНАЛИЗА ФИНАНСОВЫХ РЕЗУЛЬТАТОВ ХОЗЯЙСТВЕННОЙ ДЕЯТЕЛЬНОСТИ ОРГАНИЗАЦИЙ

Остающаяся в распоряжении предприятия после внесения налогов и других платежей в бюджет прибыль характеризует конечный финансовый результат деятельности предприятия и называется чистой прибылью

$$
\Pi_{\text {чист }}=\Pi_{\text {дн }}-\mathrm{H},
$$

где $\Pi_{\text {чист }}$ - чистая прибыль, $\mathrm{p}$; $\mathrm{H}$ - сумма начисленных налогов и сборов, $\mathrm{p}$.

Затем проводится горизонтальный, вертикальный и трендовый анализ отчета о финансовых результатах.

Третий этап - факторный анализ финансовых результатов. Определяются факторы, влияющие на каждый вид прибыли (количество и качество продукции, себестоимость продукции, цены на продукцию, элементы себестоимости, структурные сдвиги в составе продукции и так далее).

Четвертый этап - оценка влияния инфляции на финансовые результаты от продаж.

На пятом этапе проводится анализ качества прибыли, а именно: расчет относительных и абсолютных изменений таких показателей, как сальдо доходов и расходов по обычным видам деятельности, сальдо операционных доходов и расходов, скорректированное сальдо прочих доходов и расходов, чистая прибыль.

Шестой этап заключается в расчете и анализе рентабельности продаж. Рассчитываются показатели рентабельности продаж по прибыли от продажи, по прибыли до налогообложения и по чистой прибыли, которые находятся как отношение данных видов прибыли к выручке от продаж [4].

Второй метод анализа финансовых результатов разработан Н. Н. Селезневой и состоит из пяти этапов:

- на первом этапе аналогично предыдущему методу формируются и рассчитываются показатели прибыли $(1-4)$;

- на втором этапе проводится оценка влияния экономических факторов на величину прибыли. В отличие от метода Шеремета факторы подразделяются на внешние и внутренние и имеют 2 порядка. Первая группа: объем реализации продукции, объем продукции по плановой себестоимости, объем продукции, обусловленный изменениями в структуре продукции. Вторая группа: снижение себестоимости продукции, снижение себестоимости за счет структурных сдвигов, динамика цен на материалы, услуги, динамика цен на рубль продукции;

- третий этап - оценка влияния инфляции на финансовые результаты;

- четвертый этап - анализ «качества» прибыли. Ведущую роль в повышении качества прибыли, по мнению автора, играет снижение себестоимости продукции путем снижения издержек либо роста цен, поэтому далее проводится факторный анализ влияния снижения себестоимости на изменение прибыли;

- последний этап - анализ рентабельности. Автор выделяет 4 показателя рентабельности: рентабельность производства, продаж, активов и собственного капитала. Для анализа показателей рентабельности используются факторный и индексный методы [3].

Последний из рассматриваемых методов разработан в программном комплексе «Инэк. Финансовый аналитик».

Методика включает:

- расчет показателей прибыли (1 - 4). Показатели таблицы финансовых результатов рассчитываются на основании данных формы бухгалтерской отчетности «Отчет о финансовых результатах» путем снятия нарастающего итога с показателей формы. Показатели прибыли рассчитываются аналогично предыдущим методикам, при этом операционные доходы и расходы входят в понятие «прочие», а сумма начисленных налогов и сборов включает отложенные налоговые обязательства, отложенные налоговые активы, текущий налог на прибыль и прочие расходы, влияющие на чистую прибыль;

- вертикальный, горизонтальный и трендовый анализ отчета о финансовых результатах;

- расчет показателей рентабельности деятельности (рентабельности всех операций по прибыли до налогообложения; всех операций по чистой прибыли; продаж (основной деятельности); продаж по чистой прибыли; реализованной продукции) и показателей рентабельности капитала 
(рентабельности активов по прибыли до налогообложения; активов по чистой прибыли; производственных активов по результатам от основной деятельности; чистых производственных активов; чистых активов по прибыли до налогообложения; собственного капитала по чистой прибыли), их факторный анализ;

- оценку эффективности деятельности (на основе расчета показателей рентабельности и оборачиваемости) и финансовой устойчивости (показатели соотношения собственного и заемного капитала, уровня собственного капитала, коэффициента обеспеченности собственными средствами и коэффициента Бивера);

- комплексную оценку финансового состояния организации. На основе интегральной оценки финансового состояния предприятие относится к одной из четырех групп. В основе интегральной оценки лежат четыре показателя: уровень собственного капитала, коэффициент покрытия внеоборотных активов собственным капиталом; длительность оборота краткосрочной задолженности по денежным платежам; длительность оборота чистого производственного оборотного капитала.

Система присвоения баллов предприятию отражена в табл. 2. Баллы по всем четырем показателям суммируются. Длительность оборота задолженности по денежным платежам и длительность оборота чистого производственного оборотного капитала для целей расчета в интервалах $-1-0$ и $0-1$ округляется по следующему принципу: если показатель не равен 0 , то он равен 1 или -1. Например, расчетный показатель длительности оборота чистого производственного оборотного капитала равен минус $-0,4$ - в таблице он будет округлен до -1. В зависимости от суммы набранных баллов предприятие можно отнести к $1-4$ группам в системе ранжирования.

Таблица 2

Система присвоения баллов предприятию

\begin{tabular}{|c|c|c|c|c|}
\hline \multirow[t]{2}{*}{ Показатель } & \multicolumn{4}{|c|}{ Значения интервала } \\
\hline & Группа 1 & Группа 2 & Группа 3 & Группа 4 \\
\hline Уровень собственного капитала, \% & $>=70$ & $60-69,999$ & $50-59,999$ & $<50$ \\
\hline $\begin{array}{l}\text { Коэффициент покрытия внеоборотных } \\
\text { активов собственным капиталом }\end{array}$ & $>1,1$ & $1,0-1,1$ & $0,8-0,999$ & $<0,8$ \\
\hline $\begin{array}{l}\text { Длительность оборота краткосрочной за- } \\
\text { Долженности по денежным платежам, дни }\end{array}$ & $1-60$ & $61-90$ & $91-180$ & $>180 ;=0$ \\
\hline $\begin{array}{l}\text { Длительность оборота чистого производ- } \\
\text { ственного оборотного капитала, дни }\end{array}$ & $1-30$ & $>30 ;(-10)-(-1)$ & $(-30)-(-11)$ & $<(-30) ;=0$ \\
\hline Цена интервала, баллы & 5 & 3 & 1 & 0 \\
\hline
\end{tabular}

Преимущество программы заключается в том, что она позволяет:

- учитывать отраслевую и хозяйственную специфику деятельности предприятий;

- использовать методику ИНЭК и собственные методики анализа;

- рассчитывать экономическую добавленную стоимость (EVA);

- сравнивать и ранжировать предприятия по различным показателям;

- прогнозировать банкротство организации с помощью моделей Альтмана, Бивера, Тафлера, Лисса и скоринговой модели;

- программа способна сформировать аналитическое финансовое заключение в текстовом виде с определением комплексной оценки финансового состояния предприятия по методике, разработанной компанией ИНЭК [6].

Для анализа финансовых результатов организации и комплексной оценки ее финансового состояния предпочтительнее подобная методика, рассматриваемая с точки зрения внутренних контрагентов, так как в системе внутрихозяйственного анализа есть возможность углубления финансового анализа за счет привлечения дополнительных данных, иными словами, имеется воз- 
Иванова А. Д., Кузнецова О. Р.

СРАВНЕНИЕ МЕТОДИК АНАЛИЗА ФИНАНСОВЫХ РЕЗУЛЬТАТОВ ХОЗЯЙСТВЕННОЙ ДЕЯТЕЛЬНОСТИ ОРГАНИЗАЦИЙ

можность проведения комплексного экономического анализа и оценки эффективности хозяйственной деятельности. Преимущества внутрихозяйственного анализа заключаются в использовании всех источников информации для оценки состояния организации; комплексности анализа и изучении всех сторон деятельности; в интеграции учета, анализа, планирования и принятия решения.

\section{ЛИТЕРАТУРА}

1. Вагазова, Г. Р. Сущность финансовых результатов деятельности предприятия / Г. Р. Вагазова // Молодой ученый. - 2015. - № 11.3. - С. 13.

2. Немцев, В. Н. Экономический анализ эффективности промышленного предприятия / В. Н. Немцев. Магнитогорск: МГТУ, 2013. - 212 с.

3. Селезнева, Н. Н. Финансовый анализ / Н. Н. Селезнева, А. Ф. Ионова. - М.: ТК Велби, 2013. - 624 с.

4. Шеремет, А. Д. Комплексный анализ хозяйственной деятельности / А. Д. Шеремет. - М.: Инфра-М, 2014. $-415 \mathrm{c}$.

5. Яцюк, Н. А. Оценка финансовых результатов деятельности предприятия / Н. А. Яцюк // Аудит и финансовый анализ. - 2015. - № 1. - С. 40.

6. Сайт программного комплекса «Инэк. Аналитик». - Режим доступа: http://www.inec.ru, свободный. Загл. с экрана. 